\title{
On the role of AtDMC1, AtRAD51 and its paralogs during Arabidopsis meiosis
}

\section{Mónica Pradillo*, Javier Varas, Cecilia Oliver and Juan L. Santos}

Departamento de Genética, Facultad de Biología, Universidad Complutense de Madrid, Madrid, Spain

\author{
Edited by: \\ Changbin Chen, University of \\ Minnesota, USA \\ Reviewed by: \\ Charles I. White, Centre National de la \\ Recherche Scientifique, France \\ Holger Puchta, Karlsruhe Institute of \\ Technology, Germany \\ *Correspondence: \\ Mónica Pradillo, Departamento de \\ Genética, Facultad de Biología, \\ Universidad Complutense de Madrid, \\ Calle José Antonio Novais 2, Madrid \\ 28040, Spain \\ e-mail:pradillo@bio.ucm.es
}

Meiotic recombination plays a critical role in achieving accurate chromosome segregation and increasing genetic diversity. Many studies, mostly in yeast, have provided important insights into the coordination and interplay between the proteins involved in the homologous recombination pathway, especially the recombinase RAD51 and the meiosisspecific DMC1. Here we summarize the current progresses on the function of both recombinases and the CX3 complex encoded by AtRAD51 paralogs, in the plant model species Arabidopsis thaliana. Similarities and differences respect to the function of these proteins in other organisms are also indicated.

Keywords: AtRAD51, AtDMC1, AtRAD51C, AtXRCC3, meiosis, homologous recombination, Arabidopsis

\section{INTRODUCTION}

More than 10 years ago the Arabidopsis nuclear genome DNA sequence was published (Arabidopsis Genome Initiative, 2000). Afterward, this species has emerged as the most important experimental system in plant science. Discoveries made in Arabidopsis during the past decade have even led to the understanding or recognition of molecular processes in other organisms, including humans (Jones et al., 2008). Thus, Arabidopsis has now become an indispensable tool to understand basic cellular processes such as meiosis, a specialized type of cell division by which sexually reproducing eukaryotes maintain their chromosome number across generations.

During meiosis two rounds of cell division follow a single round of DNA replication to produce haploid gametes. The physical connections between homologous chromosomes (chiasmata) produced as consequence of reciprocal recombination events [crossovers $(\mathrm{COs})]$, in combination with sister chromatid arm cohesion, are responsible for the correct bi-orientation of bivalents at metaphase I and the subsequent segregation of a complete set of chromosomes at anaphase I. Sister chromatids separate at the second division generating haploid gametes. Fusion of gametes at fertilization restores the diploid chromosome number of the species and initiates zygote development. Most knowledge of this process, specifically on recombination mechanisms, derives from studies in Saccharomyces cerevisiae and Schizosaccharomyces pombe. However, during the past decade, analysis of meiotic homologous recombination (HR) has been boosted by the combination of forward (from phenotype to genotype) and reverse (from genotype to phenotype) genetics in Arabidopsis (Mercier and Grelon, 2008; Osman et al., 2011). Another approaches to identify meiotic genes in this species have consisted on evaluation of transcriptome profiling from flower buds, anthers and meiocytes (Schmid et al., 2005; Zhang et al., 2005; Wijeratne et al., 2007; Chen et al., 2010; Libeau et al., 2011; Yang et al., 2011), and the proteome profiling from anthers of the close relative Brassica oleracea (Sánchez-Morán et al., 2005). On these grounds, numerous data on the mechanism, specificity and regulation of meiosis have been accumulated. Moreover, plants have an advantage over other eukaryotes because their meiosis is completed (not arrested) in mutants defective in recombination, synapsis or segregation (Jones and Franklin, 2008; Wijnker and Schnittger, 2013). The present review analyzes the current knowledge about the process of meiotic HR in Arabidopsis, and is mainly focused on the role of AtRAD51 and AtDMC1 and the CX3 complex, which is encoded by AtRAD51 paralogs.

\section{INITIATION OF MEIOTIC RECOMBINATION IN Arabidopsis}

One feature that distinguishes model organisms in relation to HR is the link between recombination and pairing. In plants, as well as in yeasts, mice and humans, and unlike fruit flies and nematodes, initiation of the recombination process is essential for accurate homologous interactions that match homologous together (Dernburg et al., 1998; McKim et al., 1998; Gerton and Hawley, 2005). HR is a process by which DNA sequences are exchanged between homologous sequences (homologous chromosomes or sister chromatids). In meiosis HR is a critical process required to repair the DNA double-strand breaks (DSBs) produced at prophase I. DSB formation is catalyzed by Spo11, which is related to the Top6A subunit of archaeal type IIB topoisomerases. It is a meiosis specific protein conserved in almost all eukaryotes (Bergerat et al., 1997; Keeney, 2001). Although it seems to be lost in Dictyostelium discoideum (Malik et al., 2007), the function of Spo11 initiating meiotic recombination seems to be universal (Dernburg et al., 1998; McKim and Hayashi-Hagihara, 1998; Romanienko and Camerini-Otero, 1999; Celerin et al., 2000; Grelon et al., 2001; Lichten, 2001; see de Massy, 2013 for a more recent review). In mice and humans there are two isoforms of SPO11, SPO11 $\alpha$ and SPO11 $\beta$. The latter one is responsible for producing most DSBs 
(Romanienko and Camerini-Otero, 1999; Bellani et al., 2010). In plants several SPO11 paralogs have been identified: there are five genes in Oryza sativa and three genes in Arabidopsis. In rice, only OsSPO11-1 and OsSPO11-4 are needed for meiosis (Yu et al., 2010; An et al., 2011). In Arabidopsis, AtSPO11-1 and AtSPO112 play a role in meiotic HR whereas AtSPO11-3 is involved in DNA endoreduplication (Hartung and Puchta, 2000; Grelon et al., 2001; Hartung et al., 2002; Sugimoto-Shirasu et al., 2002; Stacey et al., 2006). There is a relatively low sequence similarity between the genes (20-30\%), suggesting they are products of an ancient duplication. AtSPO11-1 and AtSPO11-2 display a non-redundant function in DSB formation and it has been suggested that both proteins could work coordinately, forming a heterodimeric complex or interacting reciprocally to get wild-type levels of DSBs (Stacey etal., 2006). The double mutant Atspo11-1 Atspo11-2 does not differ phenotypically from the respective single ones, hence both proteins would be required for the same step in the pathway. Hartung et al. (2007a) even proposed that each DNA strand could be broken by different AtSPO11 proteins. However, Shingu et al. (2010) have described a multimeric active form of AtSPO11-1.

In Saccharomyces cerevisiae the meiotic DSB formation depends on Spo1 1 and at least nine more proteins (Keeney, 2001,2008) and the same occurs in Schizosaccharomyces pombe for Rec12 (Rec12 is the Spo11 ortholog in this species; Davis and Smith, 2001; Young et al., 2004). Only some of these proteins are conserved in Arabidopsis, but they do not participate in DSB formation (Edlinger and Schlögelhofer, 2011). For example, the tight dependence of Spol1 cleave on the MRX complex is not conserved in Arabidopsis (Gallego et al., 2001; Bleuyard et al., 2004; Puizina et al., 2004; Akutsu et al., 2007). Likewise, Ski8 orthologs are required for DSB formation in S. cerevisiae, S. pombe and Sordaria, but in Arabidopsis Ski8 is dispensable for meiosis (Jolivet et al., 2006). On the other hand, forward genetic approaches have led to identification of other genes necessary for DSB formation in Arabidopsis: AtPRD1, AtPRD2, and AtPRD3 (De Muyt et al., 2007, 2009). These authors suggested that AtPRD1 could contribute to generate an asymmetry in DSB processing. Although an AtPRD1 ortolog has not been found in fungi, there is a similarity between AtPRD1 and MEI1 and between AtPRD2 and MEI4. Both, MEI1 and MEI4, are involved in the first steps of mammalian meiosis (Libby et al., 2003; Kumar et al., 2010). Also, PAIR1, the rice ortholog or AtPRD3, is required for DSB formation (Nonomura et al., 2004). Another Arabidopsis DSB forming protein recently discovered is Arabidopsis thaliana DSB formation (AtDFO), a plant-specific protein without any known conserved domain (Zhang et al., 2012). These findings suggest that, although the DSB formation by Spo11 is well conserved, there are significant mechanistic differences in the regulation of this process in different organisms.

\section{REPAIR OF DOUBLE-STRAND BREAKS BY HOMOLOGOUS RECOMBINATION: CROSSOVERS AND NON-CROSSOVER}

A HR event between two homologous sequences can result in either $\mathrm{CO}$ or non-CO (NCO). In COs there is a reciprocal exchange of alleles flanking the DSB position, the formation of at least one CO (the obligatory chiasma) is necessary to hold homologous chromosomes together until their segregation to opposite poles at anaphase I. In NCOs, which are also formed associated to CO events, flanking alleles maintain their original linkage. The current model to explain meiotic HR was proposed in yeast by Bishop and Zickler (2004). It broadly concurs with a previous model (Szostak et al., 1983; Sun et al., 1989) modified by Stahl (1994), with the exception that the $\mathrm{CO} / \mathrm{NCO}$ decision is made earlier, before double Holliday junction $(\mathrm{dHJ})$ resolution and synaptonemal complex (SC) formation (Allers and Lichten, 2001). This model is apparently suitable for Arabidopsis (Ma, 2006; Sanchez-Moran et al., 2008). Figure 1 illustrates the main steps of the Arabidopsis meiotic recombination pathway and the proteins involved. In this model, NCOs may be produced by synthesis-dependent strand-annealing (SDSA), which is a mechanism involving strand invasion, DNA synthesis and strand ejection that does not involve HJs. However, SDSA is not the only way to produce NCO during meiosis in this species. Thus, AtTOP $\alpha \alpha$ and AtRMI1, which constitute a complex with a RecQ helicase, contribute to dissolve dHJs and generate some NCO products (Chelysheva et al., 2008; Hartung et al., 2008). In yeast, the helicase Sgs1 is the master controller of meiotic recombination and determines whether a recombination intermediate becomes either a NCO product or is directed toward a pathway that ultimately ends up as a CO (De Muyt et al., 2012; Zakharyevich et al., 2012). Expression of AtRECQ4A in yeast, the Arabidopsis Sgs1 ortholog, resulted in full suppression of the $s g s 1$ mutant phenotype, indicating that both proteins apparently play the same function (Bagherieh-Najjar et al., 2005; Hartung et al., 2007b). However, AtRECQ4A does not seem to play a prevalent role on CO formation (Higgins et al., 2011). In addition, DNA translocase Fanconi anemia complementation group $\mathrm{M}$ (FANCM) acts as an antirecombinase, processing meiotic DSB repair intermediates and driving them toward NCO, constraining CO formation (Crismani et al., 2012; Knoll et al., 2012).

Crossovers are originated by two different ways: class I COs are interference sensitive (subject to nearby COs) and dependent on the ZMM proteins (Börner et al., 2004), whereas class II COs are randomly distributed and dependent on Mus81 and Mms4 proteins for their formation (de los Santos et al., 2003). Here the word "interference" refers to positive interference, which is the spacing of events that departs from a random distribution. Although both CO classes are initiated by DSBs, they are generated through different intermediates: single Holliday Junctions (sHJs) for class II COs and dHJs for class I COs. Different model organisms are dependent on both $\mathrm{CO}$ classes in a different way: in fission yeast there are not interference sensitive COs (Osman et al., 2003; Smith et al., 2003; Cromie etal., 2006), whereas in Caenorhabditis elegans all COs show interference (Zalevsky et al., 1999; Hillers and Villeneuve, 2003). An intermediate situation is found in budding yeast, mammals and Arabidopsis, whose proteins required for both $\mathrm{CO}$ classes are present (Copenhaver et al., 2002; de los Santos et al., 2003; Housworth and Stahl, 2003; Berchowitz et al., 2007; Higgins et al., 2008a,b; Holloway et al., 2008). In Drosophila melanogaster all COs are produced by a third CO pathway (Yildiz et al., 2002) and associated with interference (McPeek and Speed, 1995). Although it is unclear why some species have conserved two CO pathways, this is a general feature in plant kingdom (Tuskan et al., 2006; Mimida et al., 2007; 


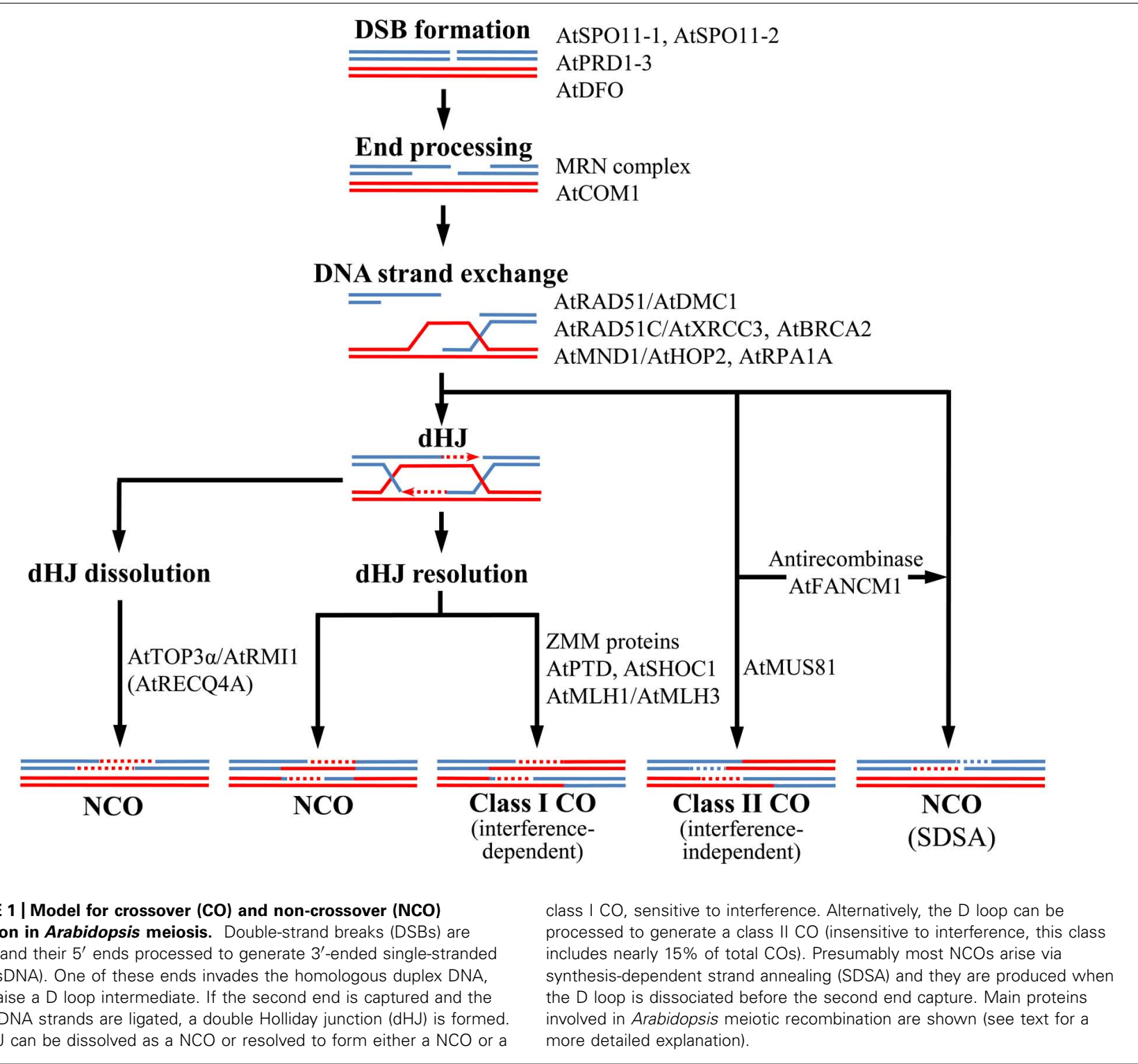

Paterson et al., 2009). Furthermore, it is possible that a third CO pathway coexists with those previously mentioned, since some COs still occurs when the main proteins involved in class I and II COs are eliminated in yeast (de los Santos et al., 2003; Argueso et al., 2004) and Arabidopsis (Berchowitz et al., 2007; Higgins et al., 2008a).

It is noteworthy that there are differences in the $\mathrm{DSBs} / \mathrm{CO}$ ratio among species (Serrentino and Borde, 2012). Neither physical genome size nor chromosome number can explain these differences. Budding yeast shows only about two times more DSBs than COs (Mancera et al., 2008). However, in Arabidopsis and mammals, precursor sites of recombination events are much more numerous than COs, suggesting that DSBs are mostly repair to give NCOs (Baudat and de Massy, 2007; Sanchez-Moran et al., 2007). In Arabidopsis, the number of NCOs per meiosis detected by different approaches [next generation sequencing (NGS); tetrad analysis; pollen typing] is, in general, very low (ranging from one to six; Lu etal., 2012; Sun et al., 2012; Drouaud et al., 2013; Wijnker et al., 2013). Since there are 120-140 DSBs in a single meiosis, as indicated by the number of AtDMC1 foci (SanchezMoran et al., 2007), and COs vary from 7 to 11 depending on the accession studied (Sanchez-Moran etal., 2002; López et al., 2012), one possible explanation for this discrepancy is inter-sister repair of DSBs. However, the relative importance of the sister as template during meiosis is totally unknown in Arabidopsis, and it seems to occur at a low frequency in other organisms (Pradillo and Santos, 2011). Other reasons for the low gene conversion rates detected could be either short NCO tracts ( $<100 \mathrm{bp}$ ), that would be undetectable because they do not convert a single nucleotide polymorphism (SNP), or the preferential repair of heteroduplexes to parental genotypes (Lu et al., 2012; Wijnker et al., 2013). On the contrary, another study using NGS approaches has concluded that between 90 and $99 \%$ of recombination events are due to gene conversion (Yang et al., 2012). Additional research 
should be addressed to confirm the discrepancy between these data.

\section{RAD51, DMC1, AND DNA STRAND EXCHANGE}

Once generated by Spo11, resection of the DSB proceeds in a $5^{\prime}-3^{\prime}$ direction, resulting in $3^{\prime}$ single-stranded tails that are required for the following step in the meiotic HR process. Following this resection, $3^{\prime}$ single-stranded DNA (ssDNA) tails are generated around the DSB site. In this context, HR occurs with a partner DNA intact duplex in a strand exchange reaction catalyzed by Rad51 (which functions during HR in all cell types) and Dmcl (the meiosisspecific recombinase) to get joint molecule intermediates (Neale and Keeney, 2006). These DNA recombinases bind to the extruded ssDNA tails, to form presynaptic filaments. Since meiotic HR possesses particular features different to mitotic HR, the preference for interactions between homologs instead of sisters among others, it has been proposed that Dmc1 is essential to carry out these unique peculiarities. Even, based on the asymmetric DSB processing, some authors have hypothesized that Rad51 and Dmcl could be loaded differentially on the distinct DNA ends (Shinohara et al., 2000; Hunter and Kleckner, 2001; Neale et al., 2005). However, despite the numerous investigations, the exactly way both recombinases work is unknown. Furthermore, there are organisms that lack a Dmcl ortholog, like Drosophila melanogaster and C. elegans. Curiously, these species achieve synapsis independently of DSBs and display COs subject to interference. This finding led Copenhaver et al. (2002) to propose that organisms possessing Dmc1 use Dmc1-mediated non-interfering COs to achieve synapsis, whereas synapsis occurs by a recombination-independent route in those lacking this protein. However, Neurospora lacks both non-interfering COs and Dmc1, but requires DSBs for synapsis (Bowring etal., 2006). On the other hand, Arabidopsis requires the early recombination function of SPO11 proteins to achieve synapsis (Grelon et al., 2001; Stacey et al., 2006), grouping with yeast, mouse, grasshopper and Coprinus, and possesses a DMC1 homolog (Kleckner, 1996; Celerin et al., 2000; Mahadevaiah et al., 2001; Viera et al., 2004).

In budding yeast, the relative importance of Rad51 and Dmc1 in promoting meiotic interhomolog instead of intersister recombination has been matter of debate in the last years. Mutants defective in Rad51 present decreased recombination in meiosis, with reduced spore viability (Petes et al., 1991), and fail to form Dmcl foci (Bishop, 1994). Mutants defective in Dmcl show defects in meiotic recombination and accumulate recombination intermediates, showing problems to form normal SCs and arresting at late prophase I (Bishop, 1994). However, Bishop et al. (1999) and Tsubouchi and Roeder (2003) demonstrated that high levels of interhomolog recombination could be achieved in the absence of Dmc1 upon either overexpression of Rad51 or its stimulating partner Rad54. These results revealed that both recombinases are able to catalyze interhomolog recombination during meiosis. Nevertheless, Rad51 strand exchange capacity during meiosis is specifically shut down by meiosis-specific factor Hed1 and Rad54 phosphorylation in such a way that interhomolog recombination is then mediated exclusively by Dmcl (Tsubouchi and Roeder, 2006; Niu et al., 2009; Busygina et al., 2012). Indeed, Cloud et al. (2012) have recently reported that only the strand exchange activity of Dmc1, and not that of Rad51, is necessary for meiotic recombination. Thus, Rad51 would be a Dmc1 accessory factor which contributes to homolog bias independently of its strand exchange activity. However, exchange activity of Rad51 may also be relevant as a fail-safe when Dmcl fails. To add more complexity to this landscape Hong et al. (2013) have reported that, contrarily it was though, the default option for recombination is homolog bias, independently whether strand exchange is promoted by either Dmc1 or Rad51. These authors proposed a model in which the role of Rad51/Dmc1 interplay for the establishment of homolog bias is to counteract a role of Rec8 that promotes sister bias. Both recombinases would contribute to homolog bias: rad51 $\Delta$ exhibits sister bias and the same occur in the double mutant hed $1 \Delta d m c 1 \Delta$ (hed $1 \Delta$ mutation permits Rad51 to carry out strand exchange when Dmc1 is absent). These authors also provide evidences for Dmc1 being an inhibitor of Rad51 activity. Recently, Lao etal. (2013) have reported a similar inhibitory function of Dmcl.

Curiously, in fission yeast the preferential polarities of Holliday junction branch migration driven by Rad51 and Dmc1 are different (Murayama et al., 2008, 2011). Despite similarities in protein structure and reaction features, Dmcl promotes exchange in the $5^{\prime}$-to- $3^{\prime}$ direction relative to the ssDNA region of the DNA substrate, while Rad51 does it in the $3^{\prime}$-to- $5^{\prime}$ direction. These differences may be important in the pathway from HR intermediate formation to CO production. Murayama et al. (2011) also proposed a role for Dmc1 in the second end capture of the DSB site.

What do we know about the function of RAD51 and DMC1 in plants? The RAD51 gene exists as a single copy in tomato and Arabidopsis, while maize has two copies (Stassen et al., 1997; Doutriaux et al., 1998; Franklin et al., 1999; Li et al., 2004). DMC1 gene sequences have been reported in a few plant species. While Arabidopsis genomes contain one copy of this gene, rice has two copies, OsDMC1A and OsDMC1B (Klimyuk and Jones, 1997; Kathiresan et al., 2002). On the contrary, there are three expressed copies of each of the TaRAD51 and TaDMC1 homoeologues in bread wheat (Devisetty et al., 2010). However, most knowledge about the function of these genes in plants has been deduced from the study of the corresponding Arabidopsis mutants. Whereas $d m c 1$ budding yeast mutants show an accumulation of unprocessed DSBs and form abnormal SCs (Bishop et al., 1992), the $d m c 1$ mutant phenotype is distinct in Arabidopsis. Atdmcl fails to undergo synapsis and displays ten unfragmented univalent chromosomes at metaphase I (Couteau et al., 1999). Thus, in this mutant the DSBs are repaired efficiently from the intact duplexes of sister chromatids, probably by AtRAD51. According with this, AtRAD51 expression, induced in young flower buds, is increased in both homozygous and heterozygous Atdmcl plants when compared with the wild-type (Couteau et al., 1999). In contrast to Atdmcl, the Atrad51 mutant exhibits meiotic defects in pairing and synapsis, as well as a severe AtSPO11-dependent chromosome fragmentation (Li et al., 2004). However, in both mutants the vegetative development is not affected, indicating that the function of both recombinases is dispensable for processing mitotic DSBs under normal growth conditions. The different phenotype of Atdmc1 and Atrad51 indicates that AtDMC1 could be primarily 
responsible for DSB repair using the homologous chromosome as a template. In contrast, AtRAD51 would repair DSBs using a sister chromatid as a template. This model has also been proposed in the protist Tetrahymena, in which in the absence of DMC1, efficient RAD51-dependent repair take place, but COs are suppressed (Howard-Till et al., 2011).

In this context, AtBRCA2 could be involved in the interplay between both recombinases, since it is required for the proper recruitment of both AtRAD51 and AtDMC1 (Seeliger et al., 2012). Likewise, an axis-associated protein related to the yeast Hop1 (ASY1), could play a role in coordinating the activity of the recombinases to favor interhomolog recombination in Arabidopsis (Sanchez-Moran et al., 2007). Thus, ASY1 has a differential effect on the localization of AtRAD51 and AtDMC1. AtRAD51 localization is independent on ASY1, but AtDMC1 fails to form a stable association with chromatin when ASY1 is absent. The disruption of AtDMC1 localization in asy1 mutant produces severe defects on chromosome alignment, synapsis and recombination, although all DSBs are repaired and chromosomes do not show fragmentation. The same occurs in the mutant $s d s$, defective for a cyclin-like protein, which also shows defects in AtDMC1 localization (De Muyt et al., 2009). On the other hand, there is a slightly asynchrony in the chromatin loading of AtRAD51 and AtDMC1. The accumulation of AtDMC1 precedes that of AtRAD51 (Sanchez-Moran et al., 2007). This fact could reflect the asymmetry in the loading of both proteins to the resected DSBs, like has also been proposed in yeast (Hunter and Kleckner, 2001). Indeed, Kurzbauer et al. (2012) have reported that AtRAD51 and AtDMC1 do not colocalize during any meiotic stage, in concordance with the hypothesis that the recombinases occupy opposite DNA ends at a DSB. These results, together with the meiotic phenotype of these mutants, lead to suggest that the AtDMC1-end would be chiefly responsible for the initial strand invasion of the homolog, whereas the AtRAD51-end would be captured at a later stage (Figure 2). However, Kurzbauer et al. (2012) have proposed that the AtDMC1-end could be able to repair from both sister chromatids and homologous chromosomes, the strand exchange activity of RAD51 being dispensable for meiosis. They inferred this conclusion from the meiotic phenotype of the double mutant atr rad51, in which meiotic DSBs are repaired to a certain extent, even resulting in bivalent formation in some meiocytes. They also confirmed that Atrad51 is defective in AtDMC1 loading, whereas AtRAD51 foci numbers are not altered in Atdmc1. It would explain the meiotic phenotype of the corresponding mutants. This fact does not occur in other species such as Tetrahymena, in which DMC1 focus formation is independent of the presence of RAD51 (Howard-Till et al., 2011). Kurzbauer et al. (2012) also argue that ATR has a pivotal role in the meiotic program and propose a model in which AtRAD51 loading attenuates ATR signaling, allowing AtDMC1 loading (see Figure 5 in Kurzbauer et al., 2012). In this model ASY1 would inhibit AtDMC1-end for DSB repair using sister chromatids as template. This model would explain why the DNA repair of meiotic DSBs is even more efficient in the triple mutant atr rad51 asy 1 than in the double mutant atr rad51. The ability to AtDMC1 to repair using the sister has also been proved in a haploid context (Crismani et al., 2013).
On the other hand, Da Ines et al. (2013a) have reported that AtRAD51 would just play a supporting role in meiotic recombination, as well as in yeast. This assertion is based on the effect of a RAD51-GFP fusion protein that retains ability to assemble at DSBs but lacks strand exchange activity. This protein is capable to repair the meiotic chromosomal fragmentation and sterility showed by Atrad51, without an increase of COs. However, this complementation is not possible in the double mutant Atrad51 Atdmc1, being fully dependent on the presence of AtDMC1. Also, another similarity between plant and yeast has been found by Uanschou et al. (2013). These authors have demonstrated that in the absence of AtDMC1, AtMND1/AtHOP2, an essential complex during $\mathrm{HR}$, is dispensable for AtRAD51-mediated intersister DNA repair. However, in the presence of AtDMC1, a minimal amount of functional AtMND1/AtHOP2 is indispensable to drive intersister DNA repair, suggesting that AtDMC1 is a negative regulator of AtRAD51 during meiosis. This negative regulation would be critical for the establishment of AtDMC1-dependent interhomolog connections.

Taking into account all the observations mentioned above, it is time to ask for the role of RAD51 during plant meiotic recombination. RAD51 is a component of the early recombination nodules, required for homology searching and synapsis in lily (Anderson et al., 1997, 2001). In maize, Franklin et al. (1999) observed that the number of RAD51 foci exceeds the number of COs. This finding led to the suggestion that these extra foci may be involved in homology search. Furthermore, Pawlowski et al. (2003) pointed out that completion of homologous pairing is necessary for the removal of RAD51 from chromosomes. In addition, maize plants deficient in RAD51 function exhibit unprocessed DSBs, as well as non-homologous synapsis and chiasmata between non-homologous chromosomes (Li et al., 2007). A knock-down Atrad51 mutant displays a similar phenotype: multivalents and well-defined homologous and non-homologous bivalents (Pradillo et al., 2012). This mutant also presents less fragmentation than the knock-out, suggesting that somehow DSBs are being processed by HR, although a critical level of AtRAD51 is required to ensure the fidelity of HR during interchromosomal exchanges. This work highlighted, for first time in Arabidopsis, that in addition to its strand exchange activity, AtRAD51 could also be required to ensure the fidelity of HR in the interchromosomal exchanges initiated by AtDMC1. Still further, Shinohara and Shinohara (2013) have recently described a role for Rad51 in the suppression of meiotic ectopic recombination in Saccharomyces cerevisiae. In summary, AtRAD51 seems to play two different, although interrelated, meiotic functions: one lying in its strand exchange activity and other lying in helping AtDMC1 to promote $\mathrm{CO}$ and to guarantee a faithful recombination. The former appears to be dispensable during the meiotic process as it has been revealed by recent studies (Kurzbauer et al., 2012; Da Ines et al., 2013a). However, in this landscape many questions remain unanswered, including the role of AtRAD51 paralogs.

\section{RAD51 PARAL0GS: THE CX3 COMPLEX}

In addition to RAD51 and DMC1, Arabidopsis, in common with vertebrates, possesses five $R A D 51$ paralogs: $R A D 51 B, R A D 51 C$, RAD51D, XRCC2, and XRCC3 (Osakabe et al., 2002; Bleuyard 
A
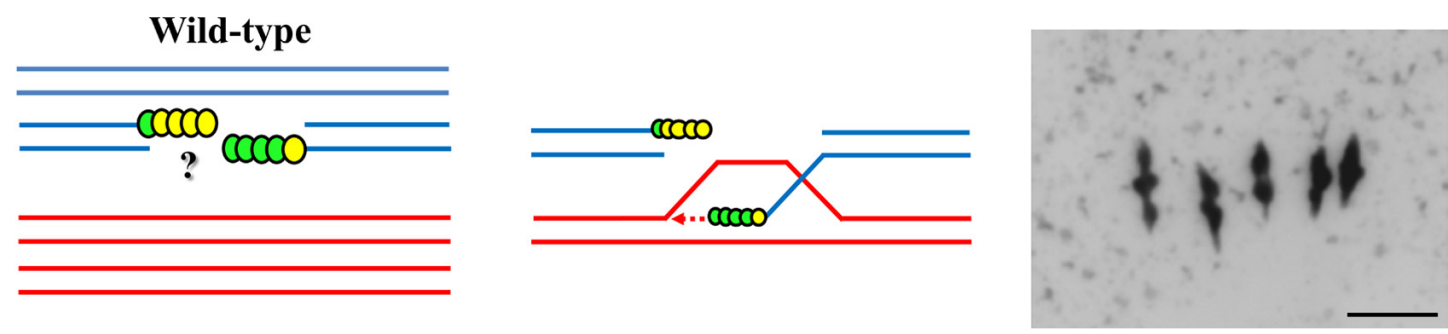

B
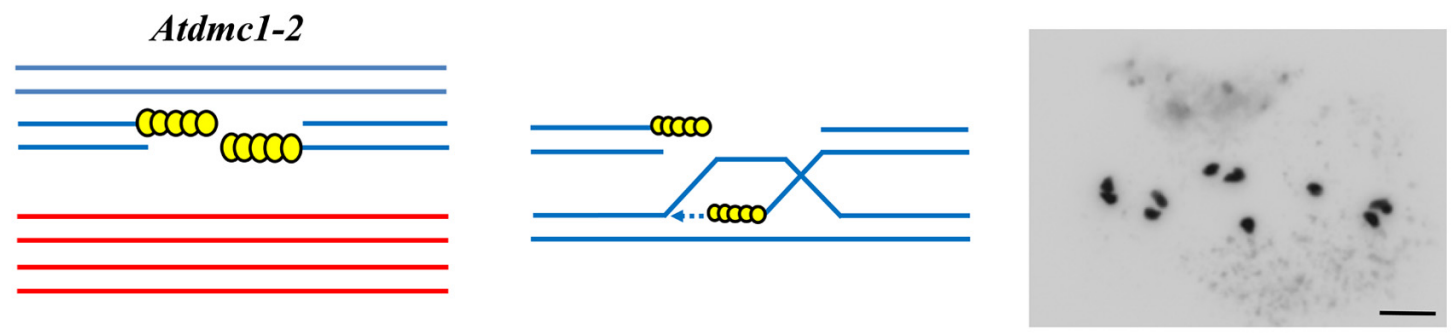

C
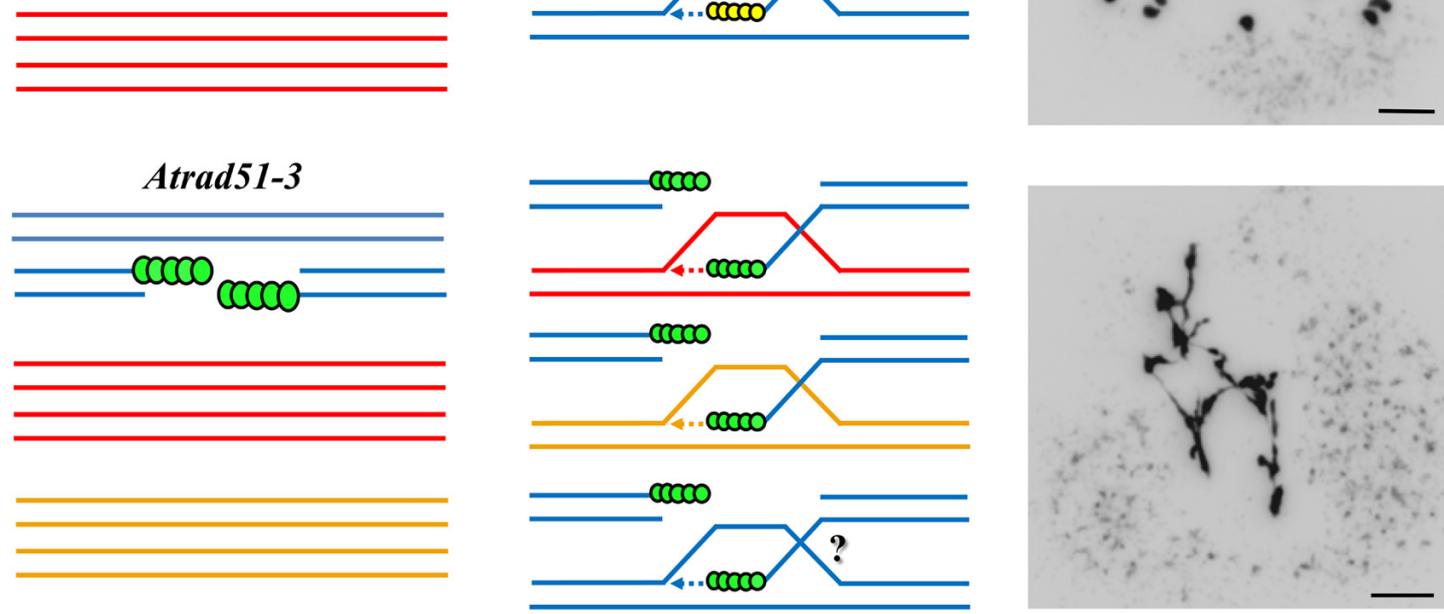

- AtRAD51 o AtDMC1

FIGURE 2 | Model for the interplay between AtRAD51 and AtDMC1 during homologous meiotic recombination in Arabidopsis. (A) During WT meiosis, it is not known if AtRAD51 (yellow) and AtDMC1 (green) are loaded asymmetrically at both DNA ends. According to several studies (see text for details) the AtDMC1 nucleofilament would be involved in the first strand invasion, whereas AtRAD51 nucleofilament would be responsible in checking homology during the second end invasion. However, the existence of mixed nucleofilaments could not be ruled out. Five bivalents are observed at metaphase I. (B) In the Atdmc1-2 mutant (Pradillo etal., 2012), all the nucleofilaments are constituted by AtRAD51. DSBs are repaired using the sister chromatid as template. The result is the formation of ten univalents at metaphase I, and complete absence of chromosome fragmentation. (C) In the Atrad51-3 mutant (knockout mutant; Pradillo etal., 2012), all the nucleofilaments are constituted by AtDMC1. The entangled mass of chromosomes observed at metaphase I could indicate recombination between homologous and non-homologous chromosomes. Sister chromatid exchanges could happen. Red and blue lines represent homologous chromatids. Orange lines represent chromatids from a non-homologous chromosome. Bars represent $5 \mu \mathrm{m}$. et al., 2005). Yeast two-hybrid and co-immunoprecipitation studies have shown that proteins coded by these RAD51 paralogs form two complexes in vertebrates: CX3 (RAD51C/XRCC3) and BCDX2 (RAD51B/C/D/XRCC2; Schild et al., 2000; Masson et al., 2001; Liu etal., 2002). Presumably these genes arose by gene duplication and acquired new functions during evolution, their exact role being not fully understood to date. Both complexes are involved in DNA repair, but only CX3 plays essential roles in meiotic HR (Bleuyard and White, 2004; Li et al., 2005; Osakabe et al., 2005). In mammals, biochemical studies have detected that in the CX3 complex, RAD51C facilitates homolog pairing, whereas XRCC3 contributes to the preferential binding of the complex to ssDNAs (Kurumizaka et al., 2001), and both proteins promote the loading of RAD51 onto DNA (Bishop et al., 1998; Masson et al., 2001; Wiese et al., 2002). It has also been proposed that CX3 functions in late stages of HR pathway, resolving Holidays junctions (Liu et al., 2004, 2007; Sharan and Kuznetsov, 2007). Recently, Chun et al. (2013) have demonstrated in human cells that in response to DNA damage, BCDX2 and CX3 complexes act upstream and downstream of RAD51 recruitment, respectively, and both are epistatic with BRCA2.

In yeast, Rad51 paralogs are named Rad55 and Rad57 and the corresponding proteins form a heterodimeric complex which associates with Rad51 nucleofilament. DSB repair defects and DNA damage sensitivity generated by mutations in these genes can be rescued by rad51 gain-of-function alleles (Fortin and Symington, 2002). Both proteins, Rad55 and Rad57, are not functionally equivalent since a mutation in the gene Rad55 has a much stronger 
effect respect to sensitivity to irradiation (Johnson and Symington, 1995). It is noteworthy that either rad55 $\Delta$ or rad57 $\Delta$ reduce interhomolog bias during meiotic recombination (Schwacha and Kleckner, 1997), but the Rad55-Rad57 complex has no strand exchange activity (Hays et al., 1995; Johnson and Symington, 1995; Sung, 1997). Their contribution to the stabilization of the Rad51 nucleofilament appears to be performed by counterbalancing the antirecombinase activity of Srs2 (Liu et al., 2011). Other novel yeast Rad51 paralogs, components of the Shu complex, also named PCSS: Shu1, Shu2, Psy3, and Csm2, have recently been identified. Their activity also counteracts the antirecombination function of Srs2 and Sgs1 (Mankouri et al., 2007; Bernstein et al., 2011; Sasanuma et al., 2013).

In Arabidopsis, AtRAD51C and AtXRCC3 are overexpressed after gamma-irradiation, indicating an essential role for these genes during DNA repair (Osakabe et al., 2002). In addition, the meiotic phenotypes of the corresponding mutants are very similar to that displayed by Atrad51 (Bleuyard and White, 2004; Abe etal., 2005; Bleuyard etal., 2005; Li et al., 2005). In this sense, the function of the CX3 complex cannot be replaced by the BCDX2 complex and Atrad51c mutation does not produce a more drastic meiotic phenotype than Atxrcc3, even though AtRAD51C is present in both complexes (Figure 3). In addition, the analysis of Atrad51c and Atxrcc3 mutants in an Atspo11-1 background has shown that their meiotic chromosomal instability comes from an inability to repair programmed DSBs (Bleuyard etal., 2004; Li etal., 2005). However, there are slightly differences that support the idea that these genes are not functionally identical to AtRAD51 since the vast majority of Atrad51-1 meiocytes do not have any SCs, whereas in Atrad51c there are occasional polycomplexes, and Atxrcc3 shows abnormal SCs at a frequency higher than those observed in Atrad51 (reviewed in $\mathrm{Ma}, 2006)$. Hence, AtRAD51C, AtXRCC3, and AtRAD51 are not genetically redundant and work together to promote the repair of meiotic DSBs (Bleuyard etal., 2006). In this context, twohybrid assays performed with Arabidopsis sequences confirmed that the CX3 complex interacts with AtRAD51 (Osakabe et al., 2002). For this reason it has been suggested that CX3 facilitates
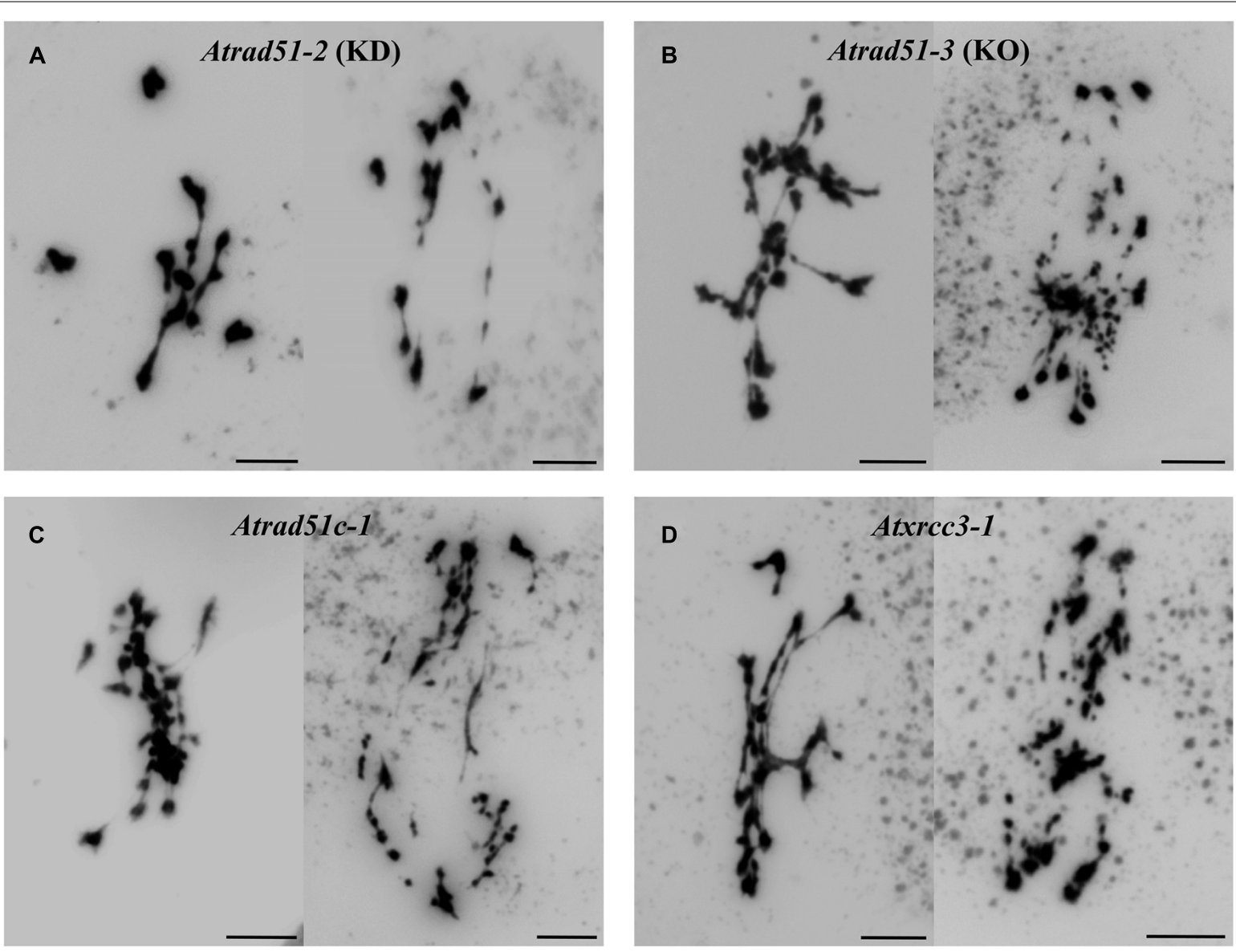

FIGURE 3 | Some examples of metaphases I and anaphases I in two Atrad51 mutants and defective mutants for the $\mathrm{CX} 3$ complex. (A) Knockdown (KD) mutant for Atrad51: Atrad51-2. (B) Knockout (KO) mutant for Atrad51: Atrad51-3 (see Pradillo etal., 2012). (C) Atrad51c-1. (D) Atxrcc3-1. The meiotic phenotype of Atrad51-3, Atrad51c-1 and Atxrcc3-1 is quite similar: an entangled mass of chromosomes involving

multivalent associations at metaphase I, and missegregations and severe chromosome fragmentation at anaphase I. This phenotype is slighter in the KD mutant Atrad51-2: three bivalents and four univalents are clearly distinguished in the picture corresponding to metaphase I. Also, chromosome fragmentation is less drastic at anaphase I. Bars represent $5 \mu \mathrm{m}$. 
the loading and/or activity of this recombinase during meiotic prophase I.

Roth etal. (2012) have verified that AtRAD51 and its paralogs AtRAD51C and AtXRCC3 are of great importance for SDSA during somatic recombination. Nevertheless, the exact role of AtRAD51C and AtXRCC3 in plant meiosis and how they collaborate with AtRAD51 to achieve efficient HR remain elusive. Vignard et al. (2007) demonstrated that in the wild-type AtDMC1 loading depends on AtRAD51 and AtXRCC3. However, in a mutant defective for the AtMND1/AtHOP2 complex, which is also essential during early stages of prophase I, AtXRCC3 is dispensable for AtDMC1 focus formation, whereas AtRAD51 is not. Based on this fact, these authors proposed a role for AtXRCC3 in stabilizing AtDMC1 nucleoprotein filaments, since its absence reduces the number of AtDMC1 foci in Atmnd1. It is not known whether AtRAD51C, which also carries out an important function during DNA repair in the BCDX2 complex, also presents this function. Furthermore, Da Ines et al. (2012) have analyzed the homologous pairing in Atrad51, Atrad51C, and Atxrcc3, suggesting a separate role for AtDMC1 and AtRAD51-AtRAD51C-AtXRCC3 in synapsis, that should be chromosome region dependent. AtDMC1 would stabilize pairing of homologous centromeric and pericentromeric regions, while AtRAD51 together with AtRAD51C and AtXRCC3 would be necessary for pairing of euchromatic chromosome arms.

With respect to the other paralogs, targeted inactivation of mouse $R A D 51 B, R A D 51 D$, and XRCC2 reveals that these genes are essential for mouse embryogenesis (Shu et al., 1999; Deans et al., 2000; Pittman and Schimenti, 2000). In contrast, these genes are not required for viability in Arabidopsis, as the triple mutant Atrad51b Atrad51d Atxrcc2 shows normal vegetative and reproductive growth (Serra et al., 2013; Wang et al., 2014). However, these mutants are hypersensitive to DNA damaging agents and the genes have partially redundant functions in DNA repair (Bleuyard et al., 2004, 2005; Osakabe et al., 2005; Durrant et al., 2007; Wang et al., 2014). Indeed, the expression of genes involved in both SDSA and single-strand annealing (SSA) pathways is affected in the triple mutant mentioned above. This variation could be a direct consequence of DNA damage, however, the fact that both bleomycin treatment and the triple mutation generate specific sets of differentially expressed genes suggests that each one has a distinct role in gene regulation (Wang et al., 2014). Concerning to this issue Serra et al. (2013) have found that AtXRCC2, AtRAD51B, and AtRAD51D are involved in SSA. Thus, these proteins participate in both RAD51-dependent (SDSA) and RAD51-independent (SSA) HR. Since the meiotic process appears to be normal in the triple mutant Atrad51b Atrad51d Atxrcc2 (Wang et al., 2014), the BCDX2 complex seems to be dispensable during meiotic recombination. However, a slight effect should not be ruled out. Indeed, Da Ines et al. (2013b) have reported that the absence of AtXRCC2, and to a lesser extent AtRAD51B, increases rates of meiotic COs. This effect does not occur with AtRAD51D, which is mainly involved in plant immune response (Durrant et al., 2007). Da Ines et al. (2013b) propose that the hyper-recombination phenotype displayed by Atxrcc 2 could be due to an increase in AtDMC1-dependent recombination promoted by a decrease in AtRAD51-dependent recombination.

\section{OPEN QUESTIONS}

Plants, particularly Arabidopsis, present apparently relaxed meiotic checkpoint and many mutants, unlike other model organisms, are viable. The exact role of AtDMC1, AtRAD51 and its paralogs in the meiotic HR is still a matter of controversy. The mechanisms through the recombinases cooperate to promote the homology search and the function of AtRAD51 paralogs in meiosis remain unknown. Although during the last years several studies have contributed to increase the knowledge of the interplay between these proteins, especially by the analysis of the meiotic phenotype of double and even triple mutants, many questions remain unanswered. Are the meiotic defects of Atrad51 mutants due to the absence of the recombinase or are consequences of a failure in AtDMC1 loading? Does the strand exchange capacity of AtRAD51 play a role during wild-type meiosis or only in certain mutants? Is AtRAD51 able to carry out interhomolog recombination in some genetic backgrounds? Are AtRAD51C and AtXRCC3 functionally equivalent? Are these proteins similarly involved in both intersister and interhomolog recombination? In addition to their early role during meiotic HR, as occur in mammals, do these proteins achieve any activity after strand invasion? Answers to these questions await development of forward-looking molecular tools, generation of new double mutants and finding of new players in this landscape. Time will tell.

\section{ACKNOWLEDGMENTS}

The group of Juan L. Santos is funded by grants from Ministerio de Economía y Competitividad of Spain (AGL2012-38852) and the European Union FP7 (Meiosys-KBBE-2009-222883).

\section{REFERENCES}

Abe, K., Osakabe, K., Nakayama, S., Endo, M., Tagiri, A., Todoriki, S., et al. (2005). Arabidopsis RAD51C gene is important for homologous recombination in meiosis and mitosis. Plant Physiol. 139, 896-908. doi: 10.1104/pp.105.065243

Akutsu, N., Iijima, K., Hinata, T., and Tauchi, H. (2007). Characterization of the plant homolog of Nijmegen breakage syndrome 1: involvement in DNA repair and recombination. Biochem. Biophys. Res. Commun. 353, 394-398. doi: 10.1016/j.bbrc.2006.12.030

Allers, T., and Lichten, M. (2001). Differential timing and control of noncrossover and crossover recombination during meiosis. Cell 106, 47-57. doi: 10.1016/S0092-8674(01)00416-0

An, X. J., Deng, Z. Y., and Wang, T. (2011). OsSpo11-4, a rice homologue of the archaeal TopVIA protein, mediates double-strand DNA cleavage and interacts with OsTopVIB. PLoS ONE 6:e20327. doi: 10.1371/journal.pone.0020327

Anderson, L. K., Hooker, K. D., and Stack, S. M. (2001). The distribution of early recombination nodules on zygotene bivalents from plants. Genetics 159, 12591269.

Anderson, L. K., Offenberg, H. H., Verkuijlen, W. M. H. C., and Heyting, C. (1997). RecA-like proteins are components of early meiotic nodules in lily. Proc. Natl. Acad. Sci. U.S.A. 94, 6868-6873. doi: 10.1073/pnas.94.13.6868

Arabidopsis Genome Initiative. (2000). Analysis of the genome sequence of the flowering plant Arabidopsis thaliana. Nature 408, 796-815. doi: 10.1038/35048692 Argueso, J. L., Wanat, J., Gemici, Z., and Alani, E. (2004). Competing crossover pathways act during meiosis in Saccharomyces cerevisiae. Genetics 168, 1805-1816. doi: 10.1534/genetics.104.032912

Bagherieh-Najjar, M. B., de Vries, O. M., Hille, J., and Dijkwel, P. P. (2005). Arabidopsis RecQI4A suppresses homologous recombination and modulates DNA damage responses. Plant J. 43, 789-798. doi: 10.1111/j.1365-313X.2005. 02501.x

Baudat, F., and de Massy, B. (2007). Regulating double-stranded DNA break repair towards crossover or non-crossover during mammalian meiosis. Chromosome Res. 15, 565-577. doi: 10.1007/s10577-007-1140-3 
Bellani, M. A., Boateng, K. A., McLeod, D., and Camerini-Otero, R. D. (2010). The expression profile of the major mouse SPO11 isoforms indicates that SPO11 $\beta$ introduces double strand breaks and suggests that SPO1 $1 \alpha$ has an additional role in prophase in both spermatocytes and oocytes. Mol. Cell. Biol. 30, 4391-4403. doi: 10.1128/MCB.00002-10

Berchowitz, L. E., Francis, K. E., Bey, A. L., and Copenhaver, G. P. (2007). The role of AtMUS81 interference-insensitive crossovers in A. thaliana. PLoS Genet. 3:e132. doi: 10.1371/journal.pgen.0030132

Bergerat, A., de Massy, B., Gadelle, D., Varoutas, P. C., Nicolas, A., and Forterre, P. (1997). An atypical topoisomerase II from Archaea with implications for meiotic recombination. Nature 386, 414-417. doi: 10.1038/386414a0

Bernstein, K. A., Reid, R. J., Sunjevaric, I., Demuth, K., Burgess, R. C., and Rothstein, R. (2011). The Shu complex, which contains Rad51 paralogues, promotes DNA repair through inhibition of the Srs2 anti-recombinase. Mol. Biol. Cell 22, 15991607. doi: 10.1091/mbc.E10-08-0691

Bishop, D. K. (1994). RecA homologs Dmcl and Rad51 interact to form multiple nuclear complexes prior to meiotic chromosome synapsis. Cell 79, 1081-1092. doi: 10.1016/0092-8674(94)90038-8.

Bishop, D. K., Ear, U., Bhattacharyya, A., Calderone, C., Beckett, M., Weichselbaum, R. R., et al. (1998). XRCC3 is required for assembly of RAD51 complexes in vivo. J. Biol. Chem. 273, 21482-21488. doi: 10.1074/jbc.273.34.21482

Bishop, D. K., Nikolski, Y., Oshiro, J., Chon, J., Shinohara, M., and Chen, X. (1999). High copy number suppression of the meiotic arrest caused by a dmcl mutation: REC114 imposes an early recombination block and RAD54 promotes a DMC1independent DSB repair pathway. Genes Cells 4, 425-444. doi: 10.1046/j.13652443.1999.00273.x

Bishop, D. K., Park, D., Xu, L. Z., and Kleckner, N. (1992). DMC1: a meiosisspecific yeast homolog of Escherichia coli recA required for recombination, synaptonemal complex formation, and cell-cycle progression. Cell 69, 439-456. doi: 10.1016/0092-8674(92)90446-J

Bishop, D. K., and Zickler, D. (2004). Early decision: meiotic crossover interference prior to stable strand exchange and synapsis. Cell 117, 9-15. doi: 10.1016/S00928674(04)00297-1

Bleuyard, J. Y., Gallego, M. E., Savigny, F., and White, C. I. (2005). Differing requirements for the Arabidopsis Rad51 paralogs in meiosis and DNA repair. Plant J. 41 533-545. doi: 10.1111/j.1365-313X.2004.02318.x

Bleuyard, J. Y., Gallego, M. E., and White, C. I. (2004). Meiotic defects in the Arabidopsis rad50 mutant point to conservation of the MRX complex function in early stages of meiotic recombination. Chromosoma 113, 197-203. doi: 10.1007/s00412-004-0309-1

Bleuyard, J. Y., Gallego, M. E., and White, C. I. (2006). Recent advances in understanding of the DNA double-strand break repair machinery of plants. DNA Rep. 5, 1-12. doi: 10.1016/j.dnarep.2005.08.017

Bleuyard, J. Y., and White, C. I. (2004). The Arabidopsis homologue of Xrcc3 plays an essential role in meiosis. EMBO J. 23, 439-449. doi: 10.1038/sj.emboj.7600055

Börner, G. V., Kleckner, N., and Hunter, N. (2004). Crossover/noncrossover differentiation, synaptonemal complex formation, and regulatory surveillance at the leptotene/zygotene transition of meiosis. Cell 117, 29-45. doi: 10.1016/S00928674(04)00292-2

Bowring, F. J., Yeadon, P. J., Stainer, R. G., and Catcheside, D. E. (2006). Chromosome pairing and meiotic recombination in Neurospora crassa spol1 mutants. Curr. Genet. 50, 115-123. doi: 10.1007/s00294-006-0066-1

Busygina, V., Saro, D., Williams, G., Leung, W. K., Say, A. F., Sehorn, M. G., et al. (2012). Novel attributes of Hed1 affect dynamics and activity of the Rad51 presynaptic filament during meiotic recombination. J. Biol. Chem. 287, 15661575. doi: 10.1074/jbc.M111.297309

Celerin, M., Merino, S. T., Stone, J. E., Menzie, A. M., and Zolan, M. E. (2000) Multiple roles of Spol1 in meiotic chromosome behavior. EMBO J. 19, 2739 2750. doi: 10.1093/emboj/19.11.2739

Chelysheva, L., Vezon, D., Belcram, K., Gendrot, G., and Grelon, M. (2008). The Arabidopsis BLAP75/Rmil homologue plays crucial roles in meiotic doublestrand break repair. PLoS Genet. 4:e1000309. doi: 10.1371/journal.pgen. 1000309

Chen, C., Farmer, A. D., Langley, R. J., Mudge, J., Crow, J. A., May, G. D., et al. (2010). Meiosis-specific gene discovery in plants: RNA-Seq applied to isolated Arabidopsis male meiocytes. BMC Plant Biol. 10:280. doi: 10.1186/1471-2229-10-280

Chun, J., Buechelmaier, E. S., and Powell, S. N. (2013). Rad51 paralog complexes BCDX2 and CX3 act at different stages in the BRCA1-BRCA2-dependent homologous recombination pathway. Mol. Cell. Biol. 33, 387-395. doi: 10.1128/MCB.00465-12

Cloud, V., Chan, Y. L., Grubb, J., Budke, B., and Bishop, D. K. (2012). Rad51 is an accessory factor for Dmcl-mediated joint molecule formation during meiosis. Science 337, 1222-1225. doi: 10.1126/science.1219379

Copenhaver, G. P., Housworth, E. A., and Stahl, F. W. (2002). Crossover interference in Arabidopsis. Genetics 160, 1631-1639.

Couteau, F., Belzille, F., Horlow, C., Grandjean, O., Vezon, D., and Doutriaux, M. P. (1999). Random chromosome segregation without meiotic arrest in both male and female meiocytes of a dmcl mutant of Arabidopsis. Plant Cell 11, 1623-1634. doi: 10.1105/tpc.11.9.1623

Crismani, W., Girard, C., Froger, N., Pradillo, M., Santos, J. L., Chelysheva, L., et al. (2012). FANCM limits meiotic crossovers. Science 336, 1588-1590. doi: $10.1126 /$ science. 1220381

Crismani, W., Portemer, V., Froger, N., Chelysheva, L., Horlow, C., Vrielynck, N., et al. (2013). MCM8 is required for a pathway of meiotic double-strand break repair independent of DMC1 in Arabidopsis thaliana. PLoS Genet. 9:e1003165. doi: 10.1371/journal.pgen.1003165

Cromie, G. A., Hyppa, R. W., Taylor, A. F., Zakharyevich, K., Hunter, N., and Smith, G. R. (2006). Single Holliday junctions are intermediates of meiotic recombination. Cell 127, 1167-1178. doi: 10.1016/j.cell.2006.09.050

Da Ines, O., Abe, K., Goubely, C., Gallego, M. E., and White, C. I. (2012). Differing requirements for $\mathrm{RAD} 51$ and $\mathrm{DMCl}$ in meiotic pairing of centromeres and chromosome arms in Arabidopsis thaliana. PLoS Genet. 8:e1002636. doi: 10.1371/journal.pgen.1002636

Da Ines, O., Degroote, F., Goubely, C., Amiard, S., Gallego, M. E., and White, C. I. (2013a). Meiotic recombination in Arabidopsis is catalysed by DMC1, with RAD51 playing a supporting role. PLoS Genet. 9:e1003787. doi: 10.1371/journal.pgen.1003787

Da Ines, O., Degroote, F., Amiard, S., Goubely, C., Gallego, M. E., and White, C. I. (2013b). Effects of XRCC2 and RAD51B mutations on somatic and meiotic recombination in Arabidopsis thaliana. Plant J. 74, 959-970. doi: $10.1111 /$ tpj.12182

Davis, L., and Smith, G. R. (2001). Meiotic recombination and chromosome segregation in Schizosaccharomyces pombe. Proc. Natl. Acad. Sci. U.S.A. 98, 8395-8402. doi: 10.1073/pnas.121005598

Deans, B., Griffin, C. S., Maconochie, M., and Thacker, J. (2000). Xrcc2 is required for genetic stability, embryonic neurogenesis and viability in mice. EMBO J. 19, 6675-6685. doi: 10.1093/emboj/19.24.6675

de los Santos, T., Hunter, N., Lee, C., Larkin, B., Loidl, J., and Hollingsworth, N. M. (2003). The Mus81/Mms4 endonuclease acts independently of double Holliday junction resolution to promote a distinct subset of crossovers during meiosis in budding yeast. Genetics 164, 81-94.

de Massy, B. (2013). Initiation of meiotic recombination: how and where? Conservation and specificities among eukaryotes. Annu. Rev. Genet. 47, 563-599. doi: 10.1146/annurev-genet-110711-155423

De Muyt, A., Jessop, L., Kolar, E., Sourirajan, A., Chen, J., Dayani, Y., et al. (2012). BLM helicase ortholog Sgs1 is a central regulator of meiotic recombination intermediate metabolism. Mol. Cell 46, 43-53. doi: 10.1016/j.molcel.2012. 02.020

De Muyt, A., Pereira, L., Vezon, D., Chelysheva, L., Gendrot, G., Chambon, A., et al. (2009). A high throughput genetic screen identifies new early meiotic recombination functions in Arabidopsis thaliana. PLoS Genet. 5:e1000654. doi: 10.1371/journal.pgen.1000654

De Muyt, A., Vezon, D., Gendrot, G., Gallois, J. L., Stevens, R., and Grelon, M. (2007). AtPRD1 is required for meiotic double strand break formation in Arabidopsis thaliana. EMBO J. 26, 4126-4137. doi: 10.1038/sj.emboj.7601815

Dernburg, A. F., McDonald, K., Moulder, G., Barstead, R., Dresser, M., and Villeneuve, A. M. (1998). Meiotic recombination in C. elegans initiates by a conserved mechanism and is dispensable for homologous chromosome synapsis. Cell 94, 387-398. doi: 10.1016/S0092-8674(00)81481-6

Devisetty, U. K., Mayes, K., and Mayes, S. (2010). The RAD51 and DMC1 homoeologous genes of bread wheat: cloning, molecular characterization and expression analysis. BMC Res. Notes 3:245. doi: 10.1186/1756-05003-245

Doutriaux, M. P., Couteau, F., Bergounioux, C., and White, C. (1998). Isolation and characterisation of the RAD51 and DMC1 homologs from Arabidopsis thaliana. Mol. Gen. Genet. 257, 283-291. doi: 10.1007/s004380050649 
Drouaud, J., Khademian, H., Giraut, L., Zanni, V., Bellalou, S., Henderson, I. R., et al. (2013). Contrasted patterns of crossover and non-crossover at Arabidopsis thaliana meiotic recombination hotspots. PLoS Genet. 9:e1003922. doi: 10.1371/journal.pgen.1003922

Durrant, W. E., Wang, S., and Dong, X. (2007). Arabidopsis SNI1 and RAD51D regulate both gene transcription and DNA recombination during the defense response. Proc. Natl. Acad. Sci. U.S.A. 104, 4223-4227. doi: 10.1073/pnas.0609357104

Edlinger, B., and Schlögelhofer, P. (2011). Have a break: determinants of meiotic DNA double strand break (DSB) formation and processing in plants. J. Exp. Bot. 62, 1545-1563. doi: 10.1093/jxb/erq421

Fortin, G. S., and Symington, L. S. (2002). Mutations in yeast Rad51 that partially bypass the requirement for Rad55 and Rad57 in DNA repair by increasing the stability of Rad51-DNA complexes. EMBO J. 21, 3160-3170. doi: 10.1093/emboj/cdf293

Franklin, A. E., McElver, J., Sunjevaric, I., Rothstein, R., Bowen, B., and Cande, W. Z. (1999). Three-dimensional microscopy of the Rad51 recombination protein during meiotic prophase. Plant Cell 11, 809-824. doi: 10.1105/tpc.11.5.809

Gallego, M. E., Jeanneau, M., Granier, F., Bouchez, D., Bechtold, N., and White, C. I. (2001). Disruption of the Arabidopsis RAD50 gene leads to plant sterility and MMS sensitivity. Plant J. 25, 31-41. doi: 10.1111/j.1365-313X.2001.00928.x

Gerton, J. L., and Hawley, R. S. (2005). Homologous chromosome interactions in meiosis: diversity amidst conservation. Nat. Rev. Genet. 6, 477-487. doi: $10.1038 / \operatorname{nrg} 1614$

Grelon, M., Vezon, D., Gendrot, G., and Pelletier, G. (2001). AtSPO11-1 is necessary for efficient meiotic recombination in plants. EMBO J. 20, 589-600. doi 10.1093/emboj/20.3.589

Hartung, F., Angelis, K. J., Meister, A., Schubert, I., Melzer, M., and Puchta, H. (2002). An archaebacterial topoisomerase homolog not present in other eukaryotes is indispensable for cell proliferation of plants. Curr. Biol. 12, 1787-1791. doi: 10.1016/S0960-9822(02)01218-6

Hartung, F., and Puchta, H. (2000). Molecular characterisation of two paralogous SPO11 homologues in Arabidopsis thaliana. Nucleic Acids Res. 28, 1548-1554. doi: 10.1093/nar/28.7.1548

Hartung, F., Suer, S., Knoll, A., Wurz-Wildersinn, R., and Puchta, H. (2008). Topoisomerase 3 alpha and RMI1 suppress somatic crossovers and are essential for resolution of meiotic recombination intermediates in Arabidopsis thaliana. PLoS Genet. 4:e1000285. doi: 10.1371/journal.pgen.1000285

Hartung, F., Wurz-Wildersinn, R., Fuchs, J., Schubert, I., Suer, S., and Puchta, H. (2007a). The catalytically active tyrosine residues of both SPO11-1 and SPO11-2 are required for meiotic double-strand break induction in Arabidopsis. Plant Cell 19, 3090-3099. doi: 10.1105/tpc.107.054817

Hartung, F., Suer, S., and Puchta, H. (2007b). Two closely related RecQ helicases have antagonistic roles in homologous recombination and DNA repair in Arabidopsis thaliana. Proc. Natl. Acad. Sci. U.S.A. 104, 18836-18841. doi: 10.1073/pnas.0705998104

Hays, S. L., Firmenich, A. A., and Berg, P. (1995). Complex formation in yeast double-strand break repair: participation of Rad51, Rad52, $\operatorname{Rad} 55$, and Rad57 proteins. Proc. Natl. Acad. Sci. U.S.A. 92, 6925-6929. doi: 10.1073/pnas.92.15.6925

Higgins, J. D., Buckling, E. F., Franklin, F. C., and Jones, G. H. (2008a). Expression and functional analysis of AtMUS81 in Arabidopsis meiosis reveals a role in the second pathway of crossing-over. Plant J. 54, 152-162. doi: 10.1111/j.1365-313X.2008.03403.x

Higgins, J. D., Vignard, J., Mercier, R., Pugh, A. G., Franklin, F. C. H., and Jones, G. H. (2008b). AtMSH5 partners AtMSH4 in the class I meiotic crossover pathway in Arabidopsis thaliana, but is not required for synapsis. Plant J. 55, 28-39. doi: 10.1111/j.1365-313X.2008.03470.x

Higgins, J. D., Ferdous, M., Osman, K., and Franklin, F. C. (2011). The RecQ helicase AtRECQ4A is required to remove inter-chromosomal telomeric connections that arise during meiotic recombination in Arabidopsis. Plant J. 65, 492-502. doi: 10.1111/j.1365-313X.2010.04438.x

Hillers, K. J., and Villeneuve, A. M. (2003). Chromosome-wide control of meiotic crossing over in C. elegans. Curr. Biol. 13, 1641-1647. doi 10.1016/j.cub.2003.08.026

Holloway, J. K., Booth, J., Edelmann, W., McGowan, C. H., and Cohen, P. E. (2008). MUS81 generates a subset of MLH1-MLH3-independent crossovers in mammalian meiosis. PLoS Genet. 4:e1000186. doi: 10.1371/journal.pgen. 1000186
Hong, S., Sung, Y., Yu, M., Lee, M., Kleckner, N., and Kim, K. P. (2013). The logic and mechanism of homologous recombination partner choice. Mol. Cell. 51, 440-453. doi: 10.1016/j.molcel.2013.08.008

Housworth, E. A., and Stahl, F. W. (2003). Crossover interference in humans. Am. J. Hum. Genet. 73, 188-197. doi: 10.1086/376610

Howard-Till, R. A., Lukaszewicz, A., and Loidl, J. (2011). The recombinases Rad51 and Dmcl play distinct roles in DNA break repair and recombination partner choice in the meiosis of Tetrahymena. PLoS Genet. 7:e1001359. doi: 10.1371/journal.pgen.1001359

Hunter, N., and Kleckner, N. (2001). The single-end invasion: an asymmetric intermediate at the double-strand break to double-Holliday junction transition of meiotic recombination. Cell 106, 59-70. doi: 10.1016/S0092-8674(01)00430-5

Johnson, R. D., and Symington, L. S. (1995). Functional differences and interactions among the putative RecA homologs Rad51, Rad55, and Rad57. Mol. Cell. Biol. 15, 4843-4850.

Jolivet, S., Vezon, D., Froger, N., and Mercier, R. (2006). Non conservation of the meiotic function of the Ski8/Rec103 homolog in Arabidopsis. Genes Cells 11, 615-622. doi: 10.1111/j.1365-2443.2006.00972.x

Jones, A. M., Chory, J., Dangl, J. L., Estelle, M., Jacobsen, S. E., Meyerowitz, E. M., et al. (2008). The impact of Arabidopsis on human health: diversifying our portfolio. Cell 133, 939-943. doi: 10.1016/j.cell.2008.05.040

Jones, G. H., and Franklin, F. C. H. (2008). "Meiosis in Arabidopsis thaliana: recombination, chromosome organization and meiotic progression," in Recombination and Meiosis; Genome Dynamics and Stability, Vol. 2, eds R. Egel and D. H. Lankenau (Berlin: Springer), 279-306.

Kathiresan, A., Khush, G. S., and Bennett, J. (2002). Two rice DMC1 genes are differentially expressed during meiosis and during haploid and diploid mitosis. Sex. Plant Reprod. 14, 257-267. doi: 10.1007/s00497-001-0113-5

Keeney, S. (2001). Mechanism and control of meiotic recombination initiation. Curr. Top. Dev. Biol. 52, 1-53. doi: 10.1016/S0070-2153(01)52008-6

Keeney, S. (2008). "Spol1 and the formation of DNA double-strand breaks in meiosis," in Recombination and Meiosis; Genome Dynamics and Stability, Vol. 2, eds R. Egel and D. H. Lankenau (Berlin: Springer), 81-123.

Kleckner, N. (1996). Meiosis: how could it work? Proc. Natl. Acad. Sci. U.S.A. 93, 8167-8174. doi: 10.1073/pnas.93.16.8167

Klimyuk, V. I., and Jones, J. D. (1997). AtDMC1, the Arabidopsis homologue of the yeast DMC1 gene: characterization, transposon-induced allelic variation and meiosis-associated expression. Plant J. 11, 1-14. doi: 10.1046/j.1365313X.1997.11010001.x

Knoll, A., Higgins, J. D., Seeliger, K., Reha, S. J., Dangel, N. J., Bauknecht, M., et al. (2012). The Fanconi anemia ortholog FANCM ensures ordered homologous recombination in both somatic and meiotic cells in Arabidopsis. Plant Cell 24, 1448-1464. doi: 10.1105/tpc.112.096644

Kumar, R., Bourbon, H. M., and de Massy, B. (2010). Functional conservation of Mei4 for meiotic DNA double-strand break formation from yeasts to mice. Genes Dev. 24, 1266-1280. doi: 10.1101/gad.571710

Kurumizaka, H., Ikawa, S., Nakada, M., Eda, K., Kagawa, W., Takata, M., et al. (2001). Homologous-pairing activity of the human DNA-repair proteins Xrcc3.Rad51C. Proc. Natl. Acad. Sci. U.S.A. 98, 5538-5543. doi: 10.1073/pnas.091603098

Kurzbauer, M. T., Uanschou, C., Chen, D., and Schlögelhofer, P. (2012). The recombinases DMC1 and RAD51 are functionally and spatially separated during meiosis in Arabidopsis. Plant Cell 24, 2058-2070. doi: 10.1105/tpc.112. 098459

Lao, J. P., Cloud, V., Huang, C. C., Grubb, J., Thacker, D., Lee, C. Y., et al. (2013). Meiotic crossover control by concerted action of Rad51-Dmcl in homolog template bias and robust homeostatic regulation. PLoS Genet. 9:e1003978. doi: 10.1371/journal.pgen. 1003978

Li, J., Harper, L. C., Golubovskaya, I., Wang, C. R., Weber, D., Meeley, R. B., et al. (2007). Functional analysis of maize RAD51 in meiosis and double-strand break repair. Genetics 176, 1469-1482. doi: 10.1534/genetics.106.062604

Li, W., Chen, C., Markmann-Mulisch, U., Timofejeva, L., Schmelzer, E., Ma, H., et al. (2004). The Arabidopsis AtRAD51 gene is dispensable for vegetative development but required for meiosis. Proc. Natl. Acad. Sci. U.S.A. 101, 10596-10601. doi: 10.1073/pnas.0404110101

Li, W., Yang, X., Lin, Z., Timofejeva, L., Xiao, R., Makaroff, C. A., et al. (2005). The AtRAD51C gene is required for normal meiotic chromosome synapsis and double-stranded break repair in Arabidopsis. Plant Physiol. 138, 965-976. doi: $10.1104 /$ pp. 104.058347 
Libby, B. J., Reinholdt, L. G., and Schimenti, J. C. (2003). Positional cloning and characterization of Meil, a vertebrate-specific gene required for normal meiotic chromosome synapsis in mice. Proc. Natl. Acad. Sci. U.S.A. 100, 15706-15711. doi: $10.1073 /$ pnas. 2432067100

Libeau, P., Durandet, M., Granier, F., Marquis, C., Berthomé, R., Renou, J. P., et al. (2011). Gene expression profiling of Arabidopsis meiocytes. Plant Biol. (Stuttg.) 13, 784-793. doi: 10.1111/j.1438-8677.2010.00435.x

Lichten, M. (2001). Meiotic recombination: breaking the genome to save it. Curr Biol. 11, R253-R256. doi: 10.1016/S0960-9822(01)00131-132

Liu, J., Renault, L., Veaute, X., Fabre, F., Stahlberg, H., and Heyer, W. D. (2011). Rad51 paralogues Rad55-Rad57 balance the antirecombinase Srs2 in Rad51 filament formation. Nature 479, 245-248. doi: 10.1038/nature10522

Liu, N., Schild, D., Thelen, M. P., and Thompson, L. H. (2002). Involvement of Rad51C in two distinct protein complexes of Rad51 paralogs in human cells. Nucleic Acids Res. 30, 1009-1015. doi: 10.1093/nar/30.4.1009

Liu, Y., Masson, J. Y., Shah, R., O’Regan, P., and West, S. C. (2004). RAD51C is required for Holliday junction processing in mammalian cells. Science 303 243-246. doi: 10.1126/science.1093037

Liu, Y., Tarsounas, M., O'regan, P., and West, S. C. (2007). Role of RAD51C and XRCC3 in genetic recombination and DNA repair. J. Biol. Chem. 282, 1973-1979. doi: 10.1074/jbc.M609066200

López, E., Pradillo, M., Oliver, C., Romero, C., Cuñado, N., and Santos, J. L. (2012). Looking for natural variation in chiasma frequency in Arabidopsis thaliana. J. Exp. Bot. 63, 887-894. doi: 10.1093/jxb/err319

Lu, P., Han, X., Qi, J., Yang, J., Wijeratne, A. J., Li, T., et al. (2012) Analysis of Arabidopsis genome-wide variations before and after meiosis and meiotic recombination by resequencing Landsberg erecta and all four products of a single meiosis. Genome Res. 22, 508-518. doi: 10.1101/gr. 127522.111

Ma, H. (2006). "A molecular portrait of Arabidopsis meiosis," in The Arabidopsis Book, eds C. R. Somerville, E. M. Meyerowitz, J. Dangl, and M. Stitt (Rockville: American Society of Plant Biologists).

Mahadevaiah, S. K., Turner, J. M., Baudat, F., Rogakou, E. P., de Boer, P., BlancoRodríguez, J., et al. (2001). Recombinational DNA double-strand breaks in mice precede synapsis. Nat. Genet. 27, 271-276. doi: 10.1038/85830

Malik, S. B., Ramesh, M. A., Hulstrand, A. M., and Logsdon, J. M. Jr. (2007) Protist homologs of the meiotic Spo11 gene and topoisomerase VI reveal an evolutionary history of gene duplication and lineage-specific loss. Mol. Biol. Evol. 24, 2827-2841. doi: 10.1093/molbev/msm217

Mancera, E., Bourgon, R., Brozzi, A., Huber, W., and Steinmetz, L. M. (2008). Highresolution mapping of meiotic crossovers and non-crossovers in yeast. Nature 454, 479-485. doi: 10.1038/nature07135

Mankouri, H. W., Ngo, H. P., and Hickson, I. D. (2007). Shu proteins promote the formation of homologous recombination intermediates that are processed by Sgs1-Rmi1-Top3. Mol. Biol. Cell 18, 4062-4073. doi: 10.1091/mbc.E0705-0490

Masson, J. Y., Tarsounas, M. C., Stasiak, A. Z., Stasiak, A., Shah, R., McIlwraith, M. J., et al. (2001). Identification and purification of two distinct complexes containing the five RAD51 paralogs. Genes Dev. 15, 3296-3307. doi: 10.1101/gad. 947001

McKim, K. S., Green-Marroquin, B. L., Sekelsky, J. J., Chin, G., Steinberg, C., Khodosh, R., et al. (1998). Meiotic synapsis in the absence of recombination. Science 279, 876-878. doi: 10.1126/science.279.5352.876

McKim, K. S., and Hayashi-Hagihara, A. (1998). mei-W68 in Drosophila melanogaster encodes a Spo11 homolog: evidence that the mechanism for initiating meiotic recombination is conserved. Genes Dev. 12, 2932-2942. doi: 10.1101/gad.12.18.2932

McPeek, M. S., and Speed, T. P. (1995). Modeling interference in genetic recombination. Genetics 139, 1031-1044.

Mercier, R., and Grelon, M. (2008). Meiosis in plants: ten years of gene discovery. Cytogenet. Genome Res. 120, 281-290. doi: 10.1159/000121077

Mimida, N., Kitamoto, H., Osakabe, K., Nakashima, M., Ito, Y., Heyer, W. D., et al. (2007). Two alternatively spliced transcripts generated from OsMUS81, a rice homolog of yeast MUS81, are up-regulated by DNA-damaging treatments. Plant Cell Physiol. 48, 648-654. doi: 10.1093/pcp/pcm029

Murayama, Y., Kurokawa, Y., Mayanagi, K., and Iwasaki, H. (2008). Formation and branch migration of Holliday junctions mediated by eukaryotic recombinases. Nature 451, 1018-1021. doi: 10.1038/nature06609
Murayama, Y., Tsutsui, Y., and Iwasaki, H. (2011). The fission yeast meiosis-specific Dmcl recombinase mediates formation and branch migration of Holliday junctions by preferentially promoting strand exchange in a direction opposite to that of Rad51. Genes Dev. 25, 516-527. doi: 10.1101/gad.1997511

Neale, M. J., and Keeney, S. (2006). Clarifying the mechanics of DNA strand exchange in meiotic recombination. Nature 442, 153-158. doi: 10.1038 /nature04885

Neale, M. J., Pan, J., and Keeney, S. (2005). Endonucleolytic processing of covalent protein-linked DNA double-strand breaks. Nature 436, 1053-1057. doi: 10.1038 /nature 03872

Niu, H., Wan, L., Busygina, V., Kwon, Y., Allen, J. A., Li, X., et al. (2009). Regulation of meiotic recombination via Mek1-mediated Rad54 phosphorylation. Mol. Cell 36, 393-404. doi: 10.1016/j.molcel.2009.09.029

Nonomura, K. I., Nakano, M., Fukuda, T., Eiguchi, M., Miyao, A., Hirochika, H., et al. (2004). The novel gene HOMOLOGOUS PAIRING ABERRATION IN RICE MEIOSIS1 of rice encodes a putative coiled-coil protein required for homologous chromosome pairing in meiosis. Plant Cell 16, 1008-1020. doi: $10.1105 /$ tpc.020701

Osakabe, K., Abe, K., Yamanouchi, H., Takyuu, T., Yoshioka, T., Ito, Y., et al. (2005). Arabidopsis Rad51B is important for double-strand DNA breaks repair in somatic cells. Plant Mol. Biol. 57, 819-833. doi: 10.1007/s11103-0052187-1

Osakabe, K., Yoshioka, T., Ichikawa, H., and Toki, S. (2002). Molecular cloning and characterization of RAD51-like genes from Arabidopsis thaliana. Plant Mol. Biol. 50, 71-81. doi: 10.1023/A:1016047231597

Osman, F., Dixon, J., Doe, C. L., and Whitby, M. C. (2003). Generating crossovers by resolution of nicked Holliday junctions: a role for Mus81-Emel in meiosis. Mol. Cell 12, 761-774. doi: 10.1016/S1097-2765(03)00343-5

Osman, K., Higgins, J. D., Sanchez-Moran, E., Armstrong, S. J., and Franklin, F. C. (2011). Pathways to meiotic recombination in Arabidopsis thaliana. New Phytol. 190, 523-544. doi: 10.1111/j.1469-8137.2011.03665.x

Paterson, A. H., Bowers, J. E., Bruggmann, R., Dubchak, I., Grimwood, J., Gundlach, H., et al. (2009). The Sorghum bicolor genome and the diversification of grasses. Nature 457, 551-556. doi: 10.1038/nature07723

Pawlowski, W. P., Golubovskaya, I. N., and Cande, W. Z. (2003). Altered nuclear distribution of recombination protein RAD51 in maize mutants suggests the involvement of RAD51 in meiotic homology recognition. Plant Cell 15, 18071816. doi: 10.1105/tpc.012898

Petes, T. D., Malone, R. E., and Symington, L. S. (1991). "Recombination in yeast," in The Molecular Biology of the Yeast Saccharomyces, eds J. R. Broach, E. Jones, and J. R. Pringle (New York: Cold Spring Harbor Laboratory), 407-522.

Pittman, D. L., and Schimenti, J. C. (2000). Midgestation lethality in mice deficient for the RecA-related gene, Rad51d/Rad5113. Genesis 26, 167-173. doi: 10.1002/(SICI)1526-968X(200003)

Pradillo, M., López, E., Linacero, R., Romero, C., Cuñado, N., Sánchez-Morán, E., et al. (2012). Together yes, but not coupled: new insights into the roles of RAD51 and DMC1 in plant meiotic recombination. Plant J. 69, 921-933. doi: 10.1111/j.1365-313X.2011.04845.X

Pradillo, M., and Santos, J. L. (2011). The template choice decision in meiosis: is the sister important? Chromosoma 120, 447-454. doi: 10.1007/s00412-011-0336-7

Puizina, I., Siroky, J., Mokros, P., Schweizer, D., and Riha, K. (2004). Mre11 deficiency in Arabidopsis is associated with chromosomal instability in somatic cells and Spo11-dependent genome fragmentation during meiosis. Plant Cell 16, 19681978. doi: 10.1105/tpc.104.022749

Romanienko, P. J., and Camerini-Otero, R. D. (1999). Cloning, characterization, and localization of mouse and human SPO11. Genomics 61, 156-169. doi: 10.1006/geno.1999.5955

Roth, N., Klimesch, J., Dukowic-Schulze, S., Pacher, M., Mannuss, A., and Puchta, H. (2012). The requirement for recombination factors differs considerably between different pathways of homologous double-strand break repair in somatic plant cells. Plant J. 72, 781-790. doi: 10.1111/j.1365-313X.2012. 05119.x

Sanchez-Moran, E., Armstrong, S. J., Santos, J. L., Franklin, F. C., and Jones, G. H. (2002). Variation in chiasma frequency among eight accessions of Arabidopsis thaliana. Genetics 162, 1415-1422.

Sánchez-Morán, E., Mercier, R., Higgins, J. D., Armstrong, S. J., Jones, G. H., and Franklin, F. C. (2005). A strategy to investigate the plant meiotic proteome. Cytogenet. Genome Res. 109, 181-189. doi: 10.1159/000082398 
Sanchez-Moran, E., Osman, K., Higgins, J. D., Pradillo, M., Cuñado, N., Jones, G. H., et al. (2008). ASY1 coordinates early events in the plant meiotic recombination pathway. Cytogenet. Genome Res. 120, 302-312. doi: 10.1159/000121079

Sanchez-Moran, E., Santos, J. L., Jones, G. H., and Franklin, F. C. H. (2007). ASY1 mediates AtDMC1-dependent interhomolog recombination during meiosis in Arabidopsis. Genes Dev. 21, 2220-2233. doi: 10.1101/gad.439007

Sasanuma, H., Tawaramoto, M. S., Lao, J. P., Hosaka, H., Sanda, E., Suzuki, M., et al. (2013). A new protein complex promoting the assembly of Rad51 filaments. Nat. Commun. 4, 1676. doi: $10.1038 /$ ncomms 2678

Schild, D., Lio, Y. C., Collins, D. W., Tsomondo, T., and Chen, D. J. (2000). Evidence for simultaneous protein interactions between human Rad51 paralogs. J. Biol. Chem. 275, 16443-16449. doi: 10.1074/jbc.M001473200

Schmid, M., Davison, T. S., Henz, S. R., Pape, U. J., Demar, M., Vingron, M., et al. (2005). A gene expression map of Arabidopsis thaliana development. Nat. Genet. 37, 501-506. doi: 10.1038/ng1543

Schwacha, A., and Kleckner, N. (1997). Interhomolog bias during meiotic recombination: meiotic functions promote a highly differentiated interhomolog-only pathway. Cell 90, 1123-1135. doi: 10.1016/S0092-8674(00)80378-5

Seeliger, K., Dukowic-Schulze, S., Wurz-Wildersinn, R., Pacher, M., and Puchta, H. (2012). BRCA2 is a mediator of RAD51- and DMC1-facilitated homologous recombination in Arabidopsis thaliana. New Phytol. 193, 364-375. doi: 10.1111/j.1469-8137.2011.03947.x

Serra, H., Da Ines, O., Degroote, F., Gallego, M. E., and White, C. I. (2013). Roles of XRCC2, RAD51B and RAD51D in RAD51-independent SSA recombination. PLoS Genet. 9:e1003971. doi: 10.1371/journal.pgen.1003971

Serrentino, M. E., and Borde, V. (2012). The spatial regulation of meiotic recombination hotspots: are all DSB hotspots crossover hotspots? Exp. Cell Res. 318, 1347-1352. doi: 10.1016/j.yexcr.2012.03.025

Sharan, S. K., and Kuznetsov, S. G. (2007). Resolving RAD51C function in late stages of homologous recombination. Cell Div. 2, 15. doi: 10.1186/1747-1028-2-15

Shingu, Y., Mikawa, T., Onuma, M., Hirayama, T., and Shibata, T. (2010). A DNA-binding surface of SPO11-1, an Arabidopsis SPO11 orthologue required for normal meiosis. FEBS J. 277, 2360-2374. doi: 10.1111/j.1742-4658.2010.07651.x

Shinohara, M., Gasior, S. L., Bishop, D. K., and Shinohara, A. (2000). Tid1/Rdh54 promotes colocalization of Rad51 and Dmc1 during meiotic recombination. Proc Natl. Acad. Sci. U.S.A. 97, 10814-10819. doi: 10.1073/pnas.97.20.10814

Shinohara, M., and Shinohara, A. (2013). Multiple pathways suppress non-allelic homologous recombination during meiosis in Saccharomyces cerevisiae. PLoS ONE 8:e63144. doi: 10.1371/journal.pone.0063144

Shu, Z., Smith, S., Wang, L., Rice, M. C., and Kmiec, E. B. (1999). Disruption of muREC2/RAD51L1 in mice results in early embryonic lethality which can be partially rescued in a p53-/- background. Mol. Cell. Biol. 19, 8686-8693.

Smith, G. R., Boddy, M. N., Shanahan, P., and Russell, P. (2003). Fission yeast Mus81.Eme1 Holliday junction resolvase is required for meiotic crossing over but not for gene conversion. Genetics 165, 2289-2293.

Stacey, N. J., Kuromori, T., Azumi, Y., Roberts, G., Breuer, C., Wada, T., et al. (2006) Arabidopsis SPO11-2 functions with SPO11-1 in meiotic recombination. Plant J. 48, 206-216. doi: 10.1111/j.1365-313X.2006.02867.x

Stahl, F. W. (1994). The Holliday junction on its thirtieth anniversary. Genetics 138, 241-246.

Stassen, N. Y., Logsdon, J. M. Jr., Vora, G. J., Offenberg, H. H., Palmer, J. D., and Zolan, M. E. (1997). Isolation and characterization of RAD51 orthologs from Coprinus cinereus and Lycopersicon esculentum, and phylogenetic analysis of eukaryotic recA homologs. Curr. Genet. 31, 144-157. doi $10.1007 / \mathrm{s} 002940050189$

Sugimoto-Shirasu, K., Stacey, N. J., Corsar, J., Roberts, K., and McCann, M. C. (2002). DNA topoisomerase VI is essential for endoreduplication in Arabidopsis. Curr. Biol. 12, 1782-1786. doi: 10.1016/S0960-9822(02)01198-3

Sun, H., Treco, D., Schultes, N. P., and Szostak, J. W. (1989). Double-strand breaks at an initiation site for meiotic gene conversion. Nature 338, 87-90. doi: $10.1038 / 338087 \mathrm{a} 0$

Sun, Y., Ambrose, J. H., Haughey, B. S., Webster, T. D., Pierrie, S. N., Muñoz, D. F., et al. (2012). Deep genome-wide measurement of meiotic gene conversion using tetrad analysis in Arabidopsis thaliana. PLoS Genet. 8:e1002968. doi: 10.1371/journal.pgen.1002968

Sung, P. (1997). Yeast Rad55 and Rad57 proteins form a heterodimer that functions with replication protein A to promote DNA strand exchange by Rad51 recombinase. Genes Dev. 11, 1111-1121. doi: 10.1101/gad.11.9.1111
Szostak, J. W., Orr-Weaver, T. L., Rothstein, R. J., and Stahl, F. W. (1983). The doublestrand-break repair model for recombination. Cell 33, 25-35. doi: 10.1016/00928674(83)90331-8

Tsubouchi, H., and Roeder, G. S. (2003). The importance of genetic recombination for fidelity of chromosome pairing in meiosis. Dev. Cell 5, 915-925. doi: 10.1016/S1534-5807(03)00357-5

Tsubouchi, H., and Roeder, G. S. (2006). Budding yeast Hed1 downregulates the mitotic recombination machinery when meiotic recombination is impaired. Genes Dev. 20, 1766-1775. doi: 10.1101/gad. 1422506

Tuskan, G. A., Difazio, S., Jansson, S., Bohlmann, J., Grigoriev, I., Hellsten, U., etal. (2006). The genome of black cottonwood, Populus trichocarpa (Torr. \& Gray). Science 313, 1596-1604. doi: 10.1126/science. 1128691

Uanschou, C., Ronceret, A., Von Harder, M., De Muyt, A., Vezon, D., Pereira, L., et al. (2013). Sufficient amounts of functional HOP2/MND1 complex promote interhomolog DNA repair but are dispensable for intersister DNA repair during meiosis in Arabidopsis. Plant Cell. doi: 10.1105/tpc.113.118521 [Epub ahead of print].

Viera, A., Santos, J. L., Page, J., Parra, M. T., Calvente, A., Cifuentes, M., et al. (2004). DNA double-strand breaks, recombination and synapsis: the timing of meiosis differs in grasshoppers and flies. EMBO Rep. 5, 385-391. doi: 10.1038/si.embor.7400112

Vignard, J., Siwiec, T., Chelysheva, L., Vrielynck, N., Gonord, F., Armstrong, S. J., et al. (2007). The interplay of RecA-related proteins and the MND1HOP2 complex during meiosis in Arabidopsis thaliana. PLoS Genet. 3:e176. doi: 10.1371/journal.pgen.0030176

Wang, Y., Xiao, R., Wang, H., Cheng, Z., Li, W., Zhu, G., et al. (2014). The Arabidopsis RAD51 paralogs RAD51B, RAD51D and XRCC2 play partially redundant roles in somatic DNA repair and gene regulation. New Phytol. 201, 292-304. doi: 10.1111/nph.12498

Wiese, C., Collins, D. W., Albala, J. S., Thompson, L. H., Kronenberg, A., and Schild, D. (2002). Interactions involving the Rad51 paralogs Rad51C and XRCC3 in human cells. Nucleic Acids Res. 30, 1001-1008. doi: 10.1093/nar/30. 4.1001

Wijeratne, A. J., Zhang, W., Sun, Y., Liu, W., Albert, R., Zheng, Z., et al. (2007). Differential gene expression in Arabidopsis wild-type and mutant anthers: insights into anther cell differentiation and regulatory networks. Plant J. 52, 14-29. doi: 10.1111/j.1365-313X.2007.03217.x

Wijnker, E., James, G. V., Ding, J., Becker, F., Klasen, J. R., Rawat V., et al. (2013). The genomic landscape of meiotic crossovers and gene conversions in Arabidopsis thaliana. Elife 2, e01426. doi: 10.7554/eLife.01426

Wijnker, E., and Schnittger, A. (2013). Control of the meiotic cell division program in plants. Plant Reprod. 26, 143-158. doi: 10.1007/s00497-0130223-x

Yang, H., Lu, P., Wang, Y., and Ma, H. (2011). The transcriptome landscape of Arabidopsis male meiocytes from high-throughput sequencing: the complexity and evolution of the meiotic process. Plant J. 65, 503-516. doi: 10.1111/j.1365313X.2010.04439.x

Yang, S., Yuan, Y., Wang, L., Li, J., Wang, W., Liu, H., et al. (2012). Great majority of recombination events in Arabidopsis are gene conversion events. Proc. Natl. Acad. Sci. U.S.A. 109, 20992-20997. doi: 10.1073/pnas. 1211827110

Yildiz, O., Majumder, S., Kramer, B., and Sekelsky, J. J. (2002). Drosophila MUS312 interacts with the nucleotide excision repair endonuclease MEI-9 to generate meiotic crossovers. Mol. Cell 10, 1503-1509. doi: 10.1016/S1097-2765(02) 00782-7

Young, J. A., Hyppa, R. W., and Smith, G. R. (2004). Conserved and nonconserved proteins for meiotic DNA breakage and repair in yeasts. Genetics 167, 593-605. doi: 10.1534/genetics.103.023762

Yu, H., Wang, M., Tang, D., Wang, K., Chen, F., Gong, Z., et al. (2010). OsSPO11-1 is essential for both homologous chromosome pairing and crossover formation in rice. Chromosoma 119, 625-636. doi: 10.1007/s00412-0100284-7

Zakharyevich, K., Tang, S., Ma, Y., and Hunter, N. (2012). Delineation of joint molecule resolution pathways in meiosis identifies a crossover-specific resolvase. Cell 149, 334-347. doi: 10.1016/j.cell.2012.03.023

Zalevsky, J., MacQueen, A., Duffy, J. B., Kemphues, K. J., and Villeneuve, A. M. (1999). Crossing over during Caenorhabditis elegans meiosis requires a conserved 
MutS-based pathway that is partially dispensable in budding yeast. Genetics 153 , 1271-1283.

Zhang, C., Song, Y., Cheng, Z. H., Wang, Y. X., Zhu, J., Ma, H., et al. (2012). The Arabidopsis thaliana DSB formation (AtDFO) gene is required for meiotic double-strand break formation. Plant J. 72, 271-281. doi: 10.1111/j.1365313X.2012.05075.x

Zhang, X., Feng, B., Zhang, Q., Zhang, D., Altman, N., and Ma, H. (2005). Genomewide expression profiling and identification of gene activities during early flower development in Arabidopsis. Plant Mol. Biol. 58, 401-419. doi: 10.1007/s11103005-5434-6

Conflict of Interest Statement: The authors declare that the research was conducted in the absence of any commercial or financial relationships that could be construed as a potential conflict of interest.
Received: 11 December 2013; accepted: 20 January 2014; published online: 17 February 2014.

Citation: Pradillo M, Varas J, Oliver C and Santos JL (2014) On the role of AtDMC1, AtRAD51 and its paralogs during Arabidopsis meiosis. Front. Plant Sci. 5:23. doi: 10.3389/fpls.2014.00023

This article was submitted to Plant Genetics and Genomics, a section of the journal Frontiers in Plant Science.

Copyright ( $\odot 2014$ Pradillo, Varas, Oliver and Santos. This is an open-access article distributed under the terms of the Creative Commons Attribution License (CC BY). The use, distribution or reproduction in other forums is permitted, provided the original author(s) or licensor are credited and that the original publication in this journal is cited, in accordance with accepted academic practice. No use, distribution or reproduction is permitted which does not comply with these terms. 